\title{
ER-2 High Altitude Reconnaissance: A Case Study
}

\author{
by W. Moore ${ }^{1}$ and T. Polzin ${ }^{2}$
}

\begin{abstract}
There is an increasing requirement for a cost-effective means of updating digital base map and natural resources information systems. The Northern Forestry Centre of Forestry Canada is cooperating with Alberta Forestry, Lands and Wildlife and United States agencies to evaluate ER-2 high altitude (i.e., about $20 \mathrm{~km}$ ) reconnaissance in Alberta. A demonstration flight was arranged on 20 July 1988 to cover flight lines from Waterton Lakes National Park to Lesser Slave Lake, and return (i.e., about $1500 \mathrm{~km}$ ). The ER-2 platform provides both the high altitude perspective of earth satellite systems and the flexibilities of aircraft. The demonstration flight carried a panoramic camera, two mapping cameras and a digital scanner that were operated simultaneously. This provided rapid, high resolution and stereoscopic coverage of large areas. The savings from improved efficiencies for base map revisions alone, using one mapping camera were greater than the costs of routine ER-2 operations over Alberta. The three other selectable sensors would also permit natural resources information system updates for only the costs of processing, interpretation and data entry. These high altitude capabilities are required for forestry in Canada.
\end{abstract}

\section{Résumé}

De plus en plus, on recherche des moyens efficaces quant aux coûts pour mettre à jour les systèmes d'information sur les ressources naturelles et les cartes de base numériques. En conséquence, le Centre de foresterie du Nord de Forêts Canada collabore avec le ministère des Forêts, des Terres et de la Faune de l'Alberta ainsi qu'avec des organismes américains afin d'évaluer la reconnaissance à haute altitude (c'est-à-dire à environ $20 \mathrm{~km}$ ), en Alberta, au moyen de la plate-forme ER-2. Le 20 juillet 1988, on a organisé un vol de démonstration allerretour (c'est-à-dire environ $1500 \mathrm{~km}$ ) sur les lignes de vol entre le parc national des Lacs Waterton et le Petit lac des Esclaves. La plate-forme procure à la perspective de haute altitude des systèmes embarqués sur satellites terrestres et la souplesse des aéronefs. Pour le vol de demonstration, on a emporté un appareil de prise de vues panoramiques, deux chambres métriques et un appareil à balayage numérique, qui ont tous fonctionné de façon simultanée. On a ainsi obtenu rapidement et à haute résolution une couverture stéréoscopique de vastes régions. Les économies découlant de l'efficacité accrue de la révision des cartes de base, au moyen d'une chambre métrique, sont à elles seules supérieures au coût du fonctionnement répétitif de la plate-forme ER-2. Les trois autres capteurs permettraient également la mise à jour des autres systèmes d'information sur les ressources naturelles au coût seulement du traitement, de l'interprétation et de l'-entrée des données. Cette capacité de fonctionnement à haute altitude est exigée pour la foresterie au Canada.

\section{Introduction}

Natural resources management requires up-to-date information (i.e., for forestry, other renewable resources, land use, etc.). The cost-effectiveness of acquiring this new information is also important during these times of limited financial resources. The US National Aeronautics and Space Administration (NASA) owns and operates ER-2 high altitude aircraft (Figure 1) as efficient data collection platforms. Several sophisticated sensors can be simultaneously carried for rapid, high resolution and stereoscopic coverage of large areas (Figure 2). The data from the interpretation and measurements of this detailed information should be critical inputs to geographic information systems (GIS) (Moore and Chow 1987). Much can be learned from the US Forest Service experience with the ER-2 in the United States, as a basis for a demonstration flight over Alberta

\section{US Experience}

The US Forest Service has been using the ER-2 operationally with the IRIS II panoramic camera for cooperative, multistate mapping of gypsy moth defoliation along the eastern seaboard of the U.S. since 1983. A feasibility/cost study of the ER-2 with the Itek IRIS II optical bar camera and Kodak SO-131 color-infrared film used both Landsat and

\footnotetext{
${ }^{1}$ Research Scientist, Northern Forestry Centre, Forestry Canada, Edmonton, Alberta.

${ }^{2} \mathrm{P} /$ Manager, Airphoto Acquisition and Reproduction, Alberta Forestry, Lands and Wildlife, Edmonton, Alberta.
}

SPOT satellite imagery as bases for comparison in the defoliation survey (Ciesla and Eav 1987). While the ER-2 would cost twice as much as the not-yet-proven capabilities of satellite systems, it had the only acceptable certainty of acquiring the time-critical information for the whole $71155 \mathrm{~km}^{2}$ of area affected. The least expensive alternative was aerial sketchmapping, but this did not provide a sufficiently detailed or reliable record. Sketchmapping might, however, be an appropriate supplement to ER-2 coverage for areas where cloud was a problem, or in more remote highlands where peak defoliation occured later. The colorinfrared film of the IRIS II panoramic camera was a permanent record, that resolved individual tree crowns. The interpretation techniques (i.e., the conversion of large quantities of raw data to useful information) resembled sketchmapping in the office at the forest manager's convenience. These interpretation techniques were described in detail by Ward et al. (1986).

There were earlier trials for mapping a mountain pine beetle outbreak in Colorado (Klein, 1982). High altitude panoramic color-infrared airphotos were determined to be comparable in overall costs and accuracies to a combination of large-scale color airphotos and sketchmapping. The same fieldwork was used for both. The IRIS II film, however, covered virtually the entire outbreak whereas just more than half the area was covered by the traditional methods. An inferior color balance in the high altitude color-infrared film was improved with \#10 red and \#20 yellow selective color filters in film duplication. 


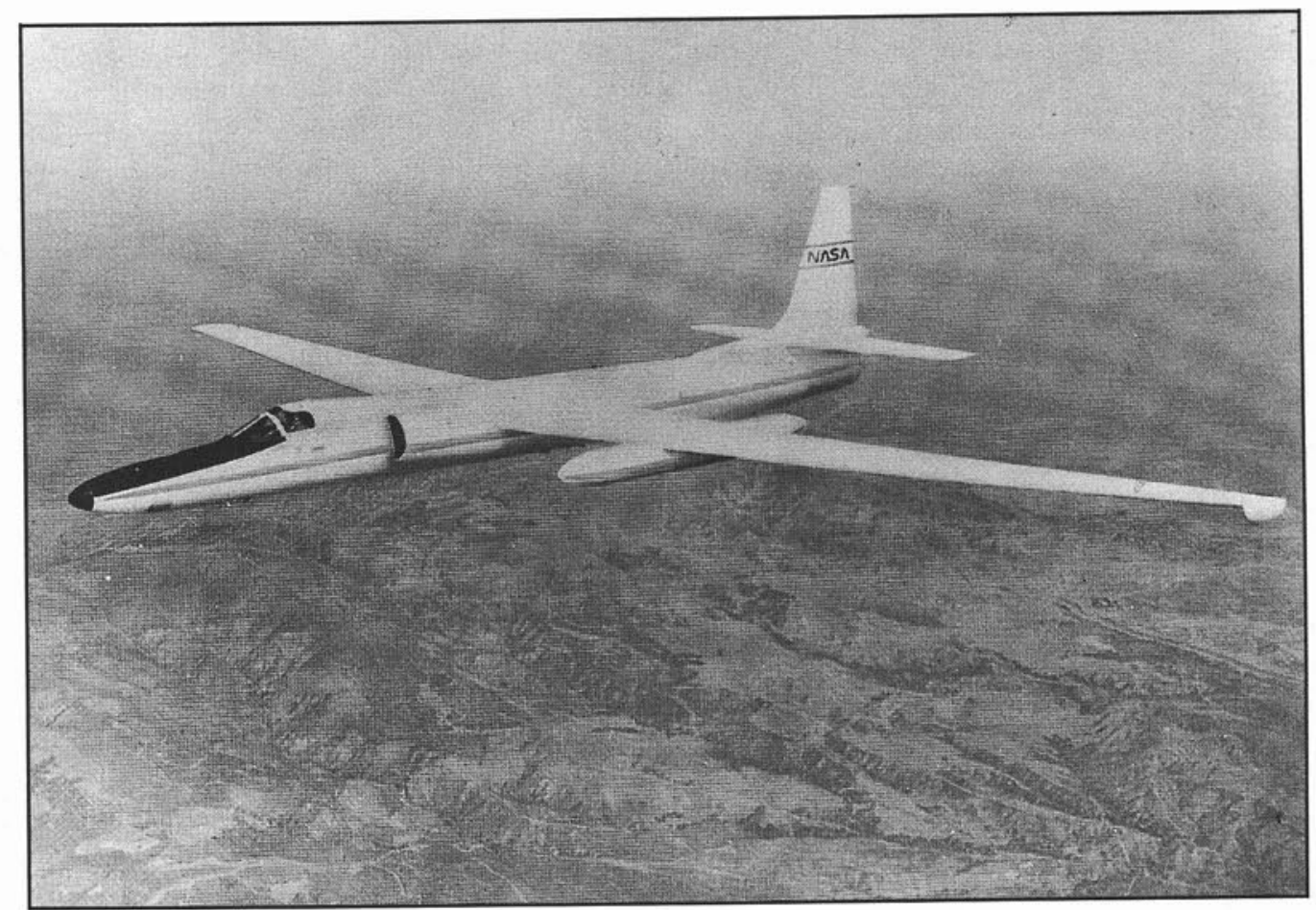

Figure 1. ER-2 high altitude aircraft (photo courtesy U.S. Forest Service).

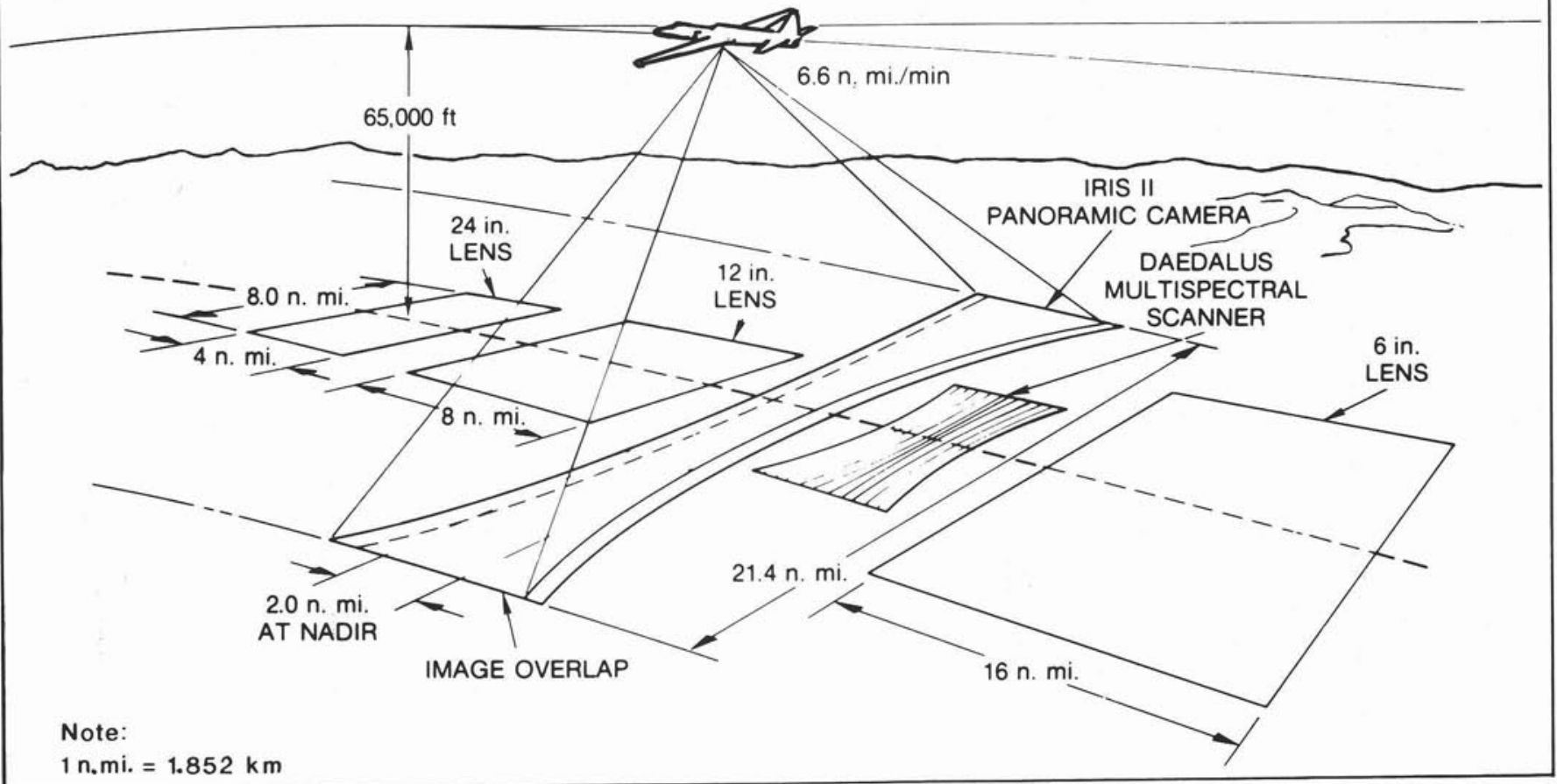

Figure 2. Sensor coverage from NASA brochure High Altitude Program. 




This is a copy of a high quality stereo-pair from segments of SO-131 color-infrared film frames taken with the Itek IRIS II Optical Bar Panoramic Camera in the ER-2 aircraft at about $20 \mathrm{~km}$ altitude. The area is within township 64, range 10, west of the 5th meridian; it is just south of the community of Swan Hills, Alberta (to the right). The original scale was 1:33 000 approximately. Tree crowns, all cut lines and well-used trails were evident in the originals. Even the markings on the highway are distinguishable in the originals.

In another trial, a GIS was used to compare the results of monoscopic interpretation of live oak decline and mortality in Texas with the IRIS II film with the results of earlier interpretation of $23 \mathrm{~cm}$ color-infrared film at 1:12 000 scale. This revealed several inconsistencies with both interpretations. The interesting lessons were that the results of older, traditional methods should never be assumed to be "ground truth", and there is no easy substitute for stereoscopic viewing and experience (Ciesla et al. 1985).

In the gypsy moth mapping experience for the eastern seaboard, the film became a permanent record that was used for many other purposes by the states involved; examples are noted below (Ciesla et al. 1984): a. mapping tree mortality in advance of cruising of proposed salvage sales;

b. examining other insect and disease problems such as red pine scale, forest tent caterpillar defoliation and southern pine beettle - also combined with egg mass survey data, public information and agricultural pest management programs;

c. evaluating spray blocks, pesticide materials, applicators, aircraft, etc., through detailed analyses of the results in the imagery;

d. planning, geological survey and water quality management;

e. nursery survey to establish priorities for on-the-ground inspections; 
f. inventory of Christmas tree plantations; and g. land use determinations.

A principal lesson from all of the foregoing seems to be that a lead opportunity or problem is required for the implementation of operational capabilities in high altitude reconnaissance. Time-critical forest insect and disease surveys appear to be the driving force in the United States. There could be a much different lead requirement in Alberta, and the development of other capabilities would follow.

\section{ER-2 Demonstration Flight}

Airborne platforms capable of acquiring very-small-scales using well-developed conventional mapping camera/film combinations have not been available in Canada in the past. The NASA ER-2 aircraft has recently been made available for forestry in Canada through the Memorandum of Understanding between Forestry Canada and the US Forest Service, which has an operating agreement with NASA. A demonstration flight was completed, 20 July 1988, through the cooperation of Forestry Canada, Alberta Forestry, Lands and Wildlife, and the US Forest Service. The flight planning was coordinated by the Northern Forestry Centre, Forestry Canada, and the funding was split between the CanadaAlberta Forest Resources Development Agreement and the Land Information Services Division of Alberta Forestry, Lands and Wildlife. The ER-2 flew from Moffett Field, California, to cover two approximately parallel flight lines between Waterton Lakes National Park and Lesser Slave Lake in Alberta (Figure 3). The films and tapes from the flight were processed, duplicated and all forwarded by the NASA/Ames Research Center, Moffett Field, California.

\section{Platform Configuration}

The ER-2 aircraft, built by the Lockheed Aircraft Corporation, is an enlarged and updated version of the US Air Force U-2 reconnaissance aircraft. The ER-2 is designed to operate at more than $20 \mathrm{~km}$ altitude at about $760 \mathrm{~km} / \mathrm{h}$ with a range of over $4800 \mathrm{~km}$. It has sensor payload compartments in two wing pods, in the nose of the aircraft, and the largest is in the fuselage behind the pilot (i.e., called the "QBay"). The flight-rated sensors available include several aerial cameras, a multi-spectral scanner, and a real-time data link. Various combinations of sensors can be carried and operated simultaneously, depending on the sensor system size and operating configuration. For instance, both the Itek IRIS II panoramic and the Actron HR 732 large format cameras require the Q-Bay, and are therefore mutually exclusive. Conventional mapping cameras and scanners, however, can be installed in any compartments (Nationwide Forestry Applications Program, 1988). The sensors used for the Alberta flights were the IRIS II panoramic and two Wild RC-10 mapping cameras, and a Thematic Mapper Simulator, for the broadest range of coverage within the single flight capability of the ER-2 aircraft.

Itek IRIS II Optical Bar Panoramic Camera. The Itek IRIS II advanced panoramic camera has a $90^{\circ}$ field of view on a $96.5 \times 11.5 \mathrm{~cm}$ film format. Film scale at nadir is about 1:32 000, with an edge scale of about 1:45 000 . The camera can hold up to $2 \mathrm{~km}$ of film for $6.5 \mathrm{~h}$ of continuous

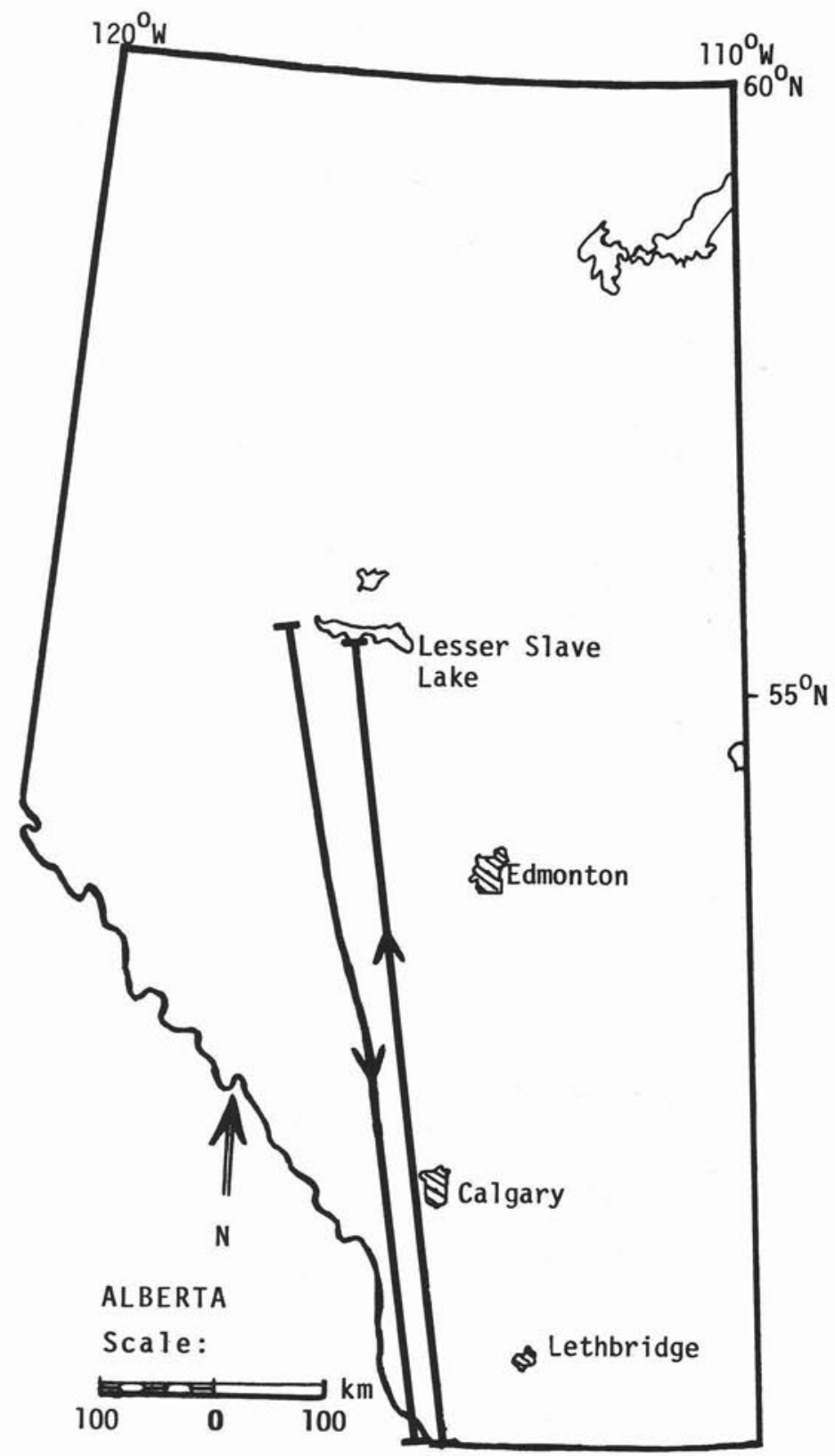

Figure 3. ER-2 1988 flight lines.

operation, but enough for $4 \mathrm{~h}$ is usually carried. The 635 $\mathrm{mm}$ focal length folded optics resemble a fore and aft horizontal periscope, or optical bar, with mirrors at either end and that is continuously rotating. It is a strip camera in that the film moves over a counter-rotating roller cage and is exposed through a variable slit aperture above the rear mirror of the optical bar. Each elongated photographic frame is a scan across the direction of flight, but is recorded successively on the film roll (Figure 4). The whole frame is in effect exposed through the centre of the lens, contributing to the high definition image. Image motion compensation is used to maintain this high definition. A structure supports the optical bar and roller assemblies, and tilts fore and aft as controlled by a velocity/altitude sensor. Stereoscopic overlap (i.e., sidelap between scans) is thus provided. The results are very even exposure of color-infrared film (i.e., haze penetration requires near-infrared film sensitivity) and 


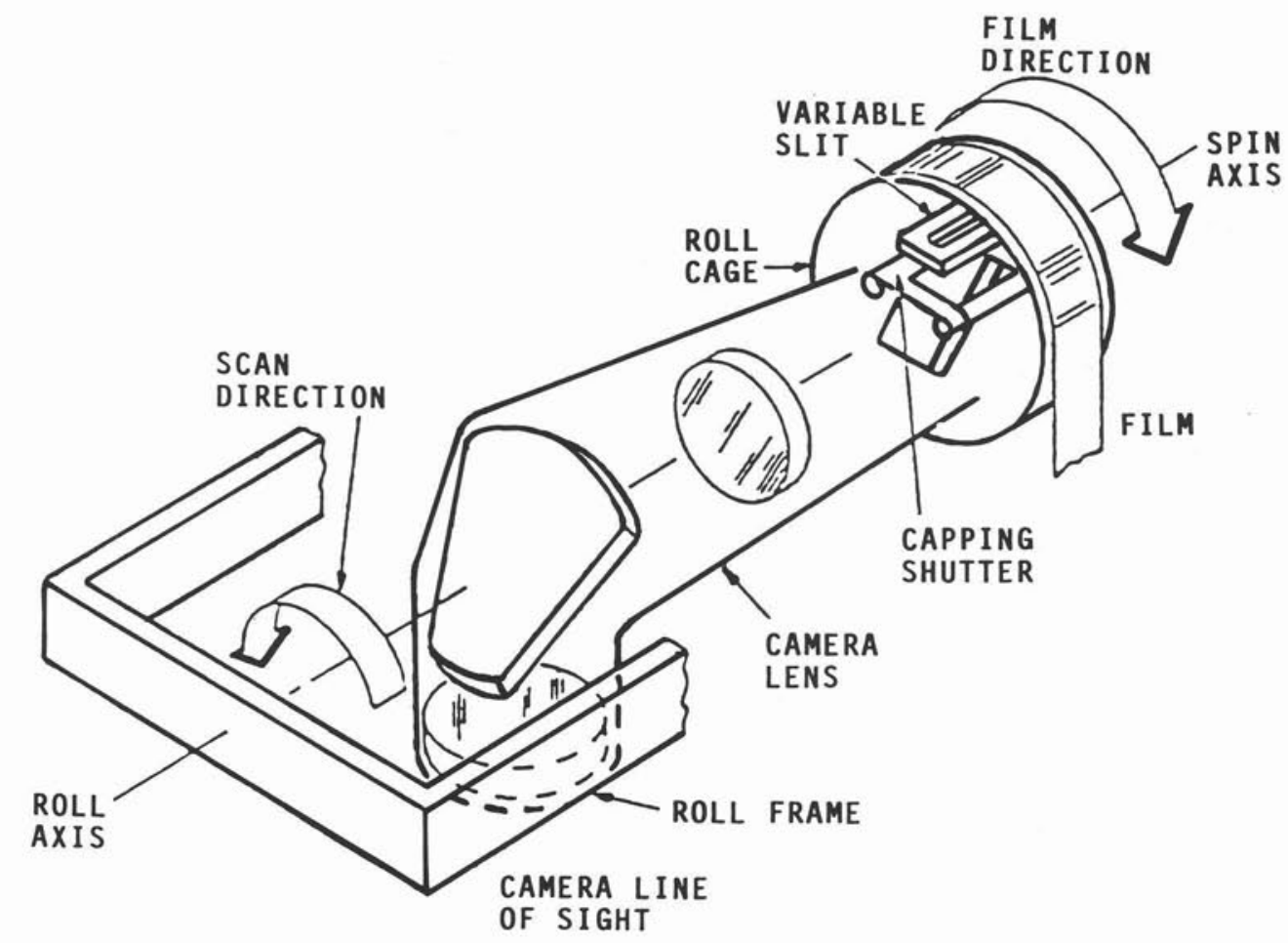

Figure 4. Optical bar concept (Nationwide Forestry Applications Program, 1988).

high definition airphotos (i.e., nominally $0.33 \mathrm{~m}$ resolution at nadir).

A thin-based high resolution color-infrared film, Kodak SO-131, was used in the IRIS II over Alberta. Kodak SO-131 film resembles conventional color-infrared film with the principal difference being the incorporation of the required minus-blue filtration in the SO-131 emulsion. The result is a regular color-infrared transparency, but with bluish background fog due to atmospheric haze. This fog is generally removed with color filters during film duplication, but with some loss of spatial definition. The enhanced duplicate appears to be very good for direct viewing and interpretation (see color stereo-pair).

Daedalus Thematic Mapper Simulator. A modified Daedalus DS 1260 multispectral scanner, comparable to the Landsat Thematic Mapper with five additional bands, was carried in an ER-2 wing pod compartment for the Alberta flight. This scanner had ten visual and near-infrared bands, between 380 and $1100 \mathrm{~nm}$, plus two thermal bands between 8.5 and $14 \mu \mathrm{m}$. The DS 1260 has an effective focal length of $150 \mathrm{~mm}$, and spatial resolution is better than $20 \mathrm{~m}$ from about $20 \mathrm{~km}$ altitude (Figure 5). Resulting data are on a magnetic tape for processing and display by digital image analysis systems.

Wild-Heerbrugg RC-10 Mapping Cameras. The two RC-10 cameras were mounted in a wing pod (with a $152 \mathrm{~mm}$ lens) and the nose compartment (with a $305 \mathrm{~mm}$ lens) for the Alberta flight. A new high definition panchromatic film (Agfa 50) was used with the $152 \mathrm{~mm}$ lens camera. This film had an extended infrared sensitivity for haze penetration, stereoscopic overlap, and a spatial resolution of better than $2 \mathrm{~m}$ at altitude (Figure 6). This combination is suitable for conventional photogrammetric mapping at small-scales, and appears to have other resource mapping and inventory potential. Further combinations with information acquired from other sources should add to this potential.

The RC-10 camera with a $305 \mathrm{~mm}$ lens was loaded with the same Kodak SO-131 color-infrared film as the IRIS II camera. It produced color transparencies at a scale of about 1:65 000. The original transparencies had a bluish appearance, much like those of the IRIS II; the color balance was also adjusted with color filtration in duplication. The usual problem with the low exposure latitude of color-infrared films was apparent, unlike the IRIS II airphotos.

\section{Discussion}

The ER-2 was evaluated as an efficient "tool" for several purposes. The greatest potential was for digital base map updating purposes. Economic inputs for natural resource management systems were also critical capabilities.

\section{Base Maps}

The Province of Alberta has established a digital base mapping program to cover all of the province at 1:20 000 scale. A five-year cycle for the revision of these base maps has been proposed. About $52 \%$ of the maps have been completed, using 1983 or earlier airphotos. This means that $52 \%$ of the maps are potentially due for map revision. A decision is now pending on a cost-effective method of acquiring revision information to maintain the usefulness of these state-of-theart digital base maps. Savings in time and money would be substantial with the ER-2, assuming the whole province could be covered and weather and scheduling were optimal. ${ }^{1}$ These savings alone are greater than the costs of ER-2 flights, but more study and experience would be required to identify break-even points for non-optimal conditions. 


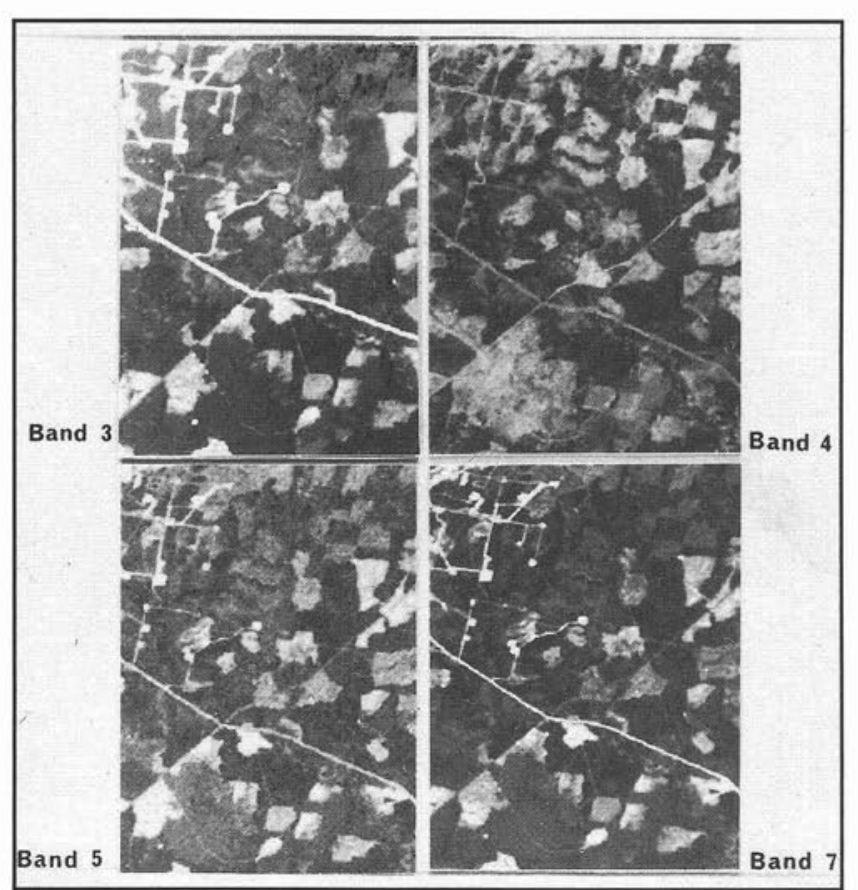

Figure 5. Thematic mapper simulator channels 5, 7, 9 and 10 of the test area; they are annotated with Landsat TM equivalents above. The original scale was 1:250 000 (approx.), with nominal $20 \mathrm{~m}$ resolution.

Base map revision tests were conducted with 1:40 000 and 1:60 000 scale survey airphotos, and a single stereo model from 1:130 000 scale Agfa 50 film acquired from the 1988 ER-2 demonstration flight. The 1:130 000 scale airphotos offered a wider selection of transfer points from the original 1:60 000 scale airphotos, and thus were the least expensive per mapsheet (i.e., $\$ 686$ compared to from $\$ 1940$ to $\$ 3060){ }^{2}$ The positional accuracies obtainable were just acceptable, but these should improve significantly with experience.

The cost of acquiring ER-2 mapping camera coverage is comparable to the cost of conventional 1:40 000 to 1:60 000 scale survey airphotos. Thus, the key to cost-effectiveness is not the acquisition of imagery, but how it is used once acquired. The cost of photogrammetric mapping relates more to the number of stereo models required than to the area covered. The significant reduction in costs of mapping from 1:130 000 scale airphotos, as opposed to $1: 40000$ or 1:60 000 scale, is a simple consequence of the scale difference (i.e., not a "linear" function, but a "square" function). This alone might justify the operational use of the ER-2 in Alberta.

In addition, orthophotos produced from the 1:130 000 scale panchromatic airphotos can be used as an interim product pending completion of the Alberta digital base maps. These orthophotos can be produced at scales ranging from 1:20 000 to $1: 60000$ from the 1:130 000 scale airphotos by utilizing existing survey control. Uncorrected enlargements

\footnotetext{
1-2A.E. Balce. Dec., 1988. Photogrammetric methods of deriving control for updating the 1:20 000 provincial digital base mapping. Alberta For. Lands Wildlife, Land Inf. Serv. Div., Surv. Control Branch, Edmonton. Internal Report, 8 pp.
}

from the 1:130 000 scale airphotos were also used directly as interim maps to take advantage of the perspective and high definition of the original airphotos. Orthophotos and enlargements can be a bridge to current mapping that supplements outdated maps and fills in areas not yet mapped. Such working "tools" were not as readily available from digital thematic mapper simulator or satellite imagery because of the order of magnitude coarser spatial resolution of those systems.

The interpretability of features in the 1:130 000 scale airphotos was an initial concern, but the availability of the IRIS II airphotos acquired at the same time allayed this concern. This advantage also means that the additional information on other resource attributes could be simultaneously acquired for the costs of processing, interpretation and data entry.

\section{Natural Resources Information}

Natural resources information have traditionally been acquired using medium-to large-scale airphotos combined with ground observations. This is in addition to the smallscale airphotos that have been used as the primary tool for base mapping. Importantly, reconnaissance forest inventories have been defined as exploratory, extensive forest inventories with no detailed estimates obtained (Haddon, 1988). The improved spatial resolution of recent earth-satellite products provides increased potential for reconnaissance levels of map updates (Moore, 1986), but the resolution and stereoscopic capabilities are still inadequate for most map revisions. The ER-2, with IRIS II camera, coverage is of significant benefit for the identification and mapping of cutlines, cutblocks, geophysical activity, burned land, insect infestations, forest regeneration, and many land use changes on a current basis.

New and more cost-effective methods for updating renewable resource management systems are constantly being evaluated. These resources are changing all the time - particularly in areas affected by settlement and industrial development. New coverage is a key component in the revision of existing mapping. Conventional small-scale airphotos have been traditionally used to update land information, but the cost of the update can approach the original cost of production. The necessary acquisition of location-specific renewable resources data can be combined with the base map updating operations with the ER-2. The same ER-2 flight that carries a RC-10 mapping camera for base map updating can also carry the IRIS II panoramic camera.

Availability and cost-effectiveness will determine which system is used for what purpose. The large discrepancies in costs and capabilities between the traditional airphotos and satellite imagery represent a significant role for ER-2 reconnaissance. The requirements for traditional methods would not disappear, but could be made much more effective within the context of more up-to-date base maps and broader, higher resolution reconnaissance in stereo. The ER-2 should be efficient and effective for such large-area reconnaissance.

\section{Conclusions}

The requirements for survey inputs to base map revisions and natural resources inventory updating are increasing with 


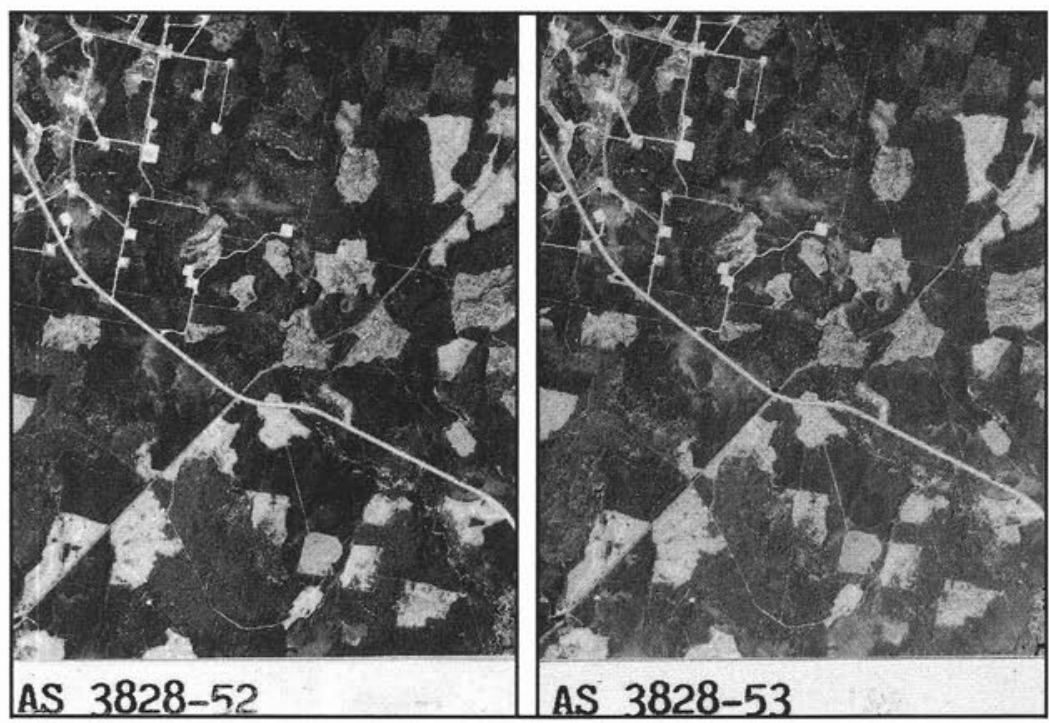

Figure 6. The above stereo pair of the test area was acquired from a RC-10 mapping camera with a $152 \mathrm{~mm}$ lens and Agfa 50 panchromatic film from about $20 \mathrm{~km}$ altitude in the ER-2 aircraft. The original scale was 1:130 000 (approx.), with nominal $4 \mathrm{~m}$ resolution.

the developments of management systems. High altitude reconnaissance with the ER-2 aircraft is a significant bridge between orbiting satellite reconnaissance and conventional aerial survey. The ER-2 is also in this mid-position in terms of costs and area coverage, but can surpass both satellites and airsurvey in sensor capabilities. The overlap with conventional aerial survey, in particular, is a key to cost-effectiveness.

The sophisticated operational capabilities of the ER-2 sensor packages have been developed elsewhere and are already available for routine operations. Further development of detailed applications for Alberta would be desireable. Further evaluation of ER-2 operations in Alberta is recommended.

\section{Acknowledgements}

Particular thanks are due Dr. Frederick P. Weber, Program Manager, Nationwide Forestry Applications Program, USDA Forest Service, Salt Lake City, Utah, for authorizing and facilitating the Alberta demonstration flights. Dr. Weber was also responsible for providing the instructors for the ER-2 workshops in Edmonton in 1988. Participants and cooperators from Forestry Canada and various agencies of the Alberta Government are too numerous to mention, but the ER-2 Project Committee consisted of: D.J. Morgan (Chairman) (Alberta Forest Service), H.A. Archibald (Land Information Branch), K. Campbell (Remote Sensing Centre), and the authors.

\section{References}

Ciesla, W.M. and B.B. Eav. 1987. Satellite imagery versus aerial photos for mapping hardwood defoliation: a preliminary evaluation of cost and acquisition feasibility. USDA For. Serv., For. Pest Manage./Methods Applic. Group, Fort Collins, CO, Rep. No. 87-2, 17 pp.
Ciesla, W.M., C.W. Dull, E.T. Wilson and P.A. Mistretta. 1985. Panoramic aerial photography for detection of oak decline and mortality in central Texas. USDA For. Serv., Pest Manage./Methods Applic. Group, Fort Collins, CO. Rep. No. 85-1, 18 pp.

Ciesla, W.M., R.E. Acciavatti, J.G.D. Ward, R.A. Allison and F.P. Weber. 1984. Demonstration of panoramic aerial photography for mapping hardwood defoliation over a multistate area of the northeastern United States. USDA For. Serv., For. Pest Manage./Methods Applic. Group, Fort Collins, CO. Rep. No. 84-3, 21 pp.

Haddon, B.D., editor. 1988. Forest Inventory Terms in Canada. 3rd ed. For. Can., Pet. Nat. For. Inst., Can. For. Invent. Comm., Chalk River, Eng./Fr., 109/113 pp.

Hinkle, R.E. 1981. High Altitude Imagery: User's Guide. USDA For. Serv., Lockheed Engineer. Manage. Serv. Co., Houston, TX. 136 pp.

Klein, W.H. 1982. Estimating bark beetle-killed lodgepole pine with high altitude panoramic photography. In Photogram. Engin. Remote Sens. 48(5) May, 733-737.

Klein, W.H. 1980(?). Understanding color infrared photography. S.F. Austin State Univ., Cent. Applied Studies, For. School, Nacogdoches, TX. 16 pp.

Moore, W.C. and W. Chow. 1987. A mapping and analysis of resources system application. For. Can., Nor. For. Cent., ENFOR, Edmonton, AB. Inf. Rep. NOR-X-285, 69 pp.

Moore, W.C. 1986. Procom-2 mapping technique for monitoring forest depletion. For. Can., Nor. For. Cent., Edmonton, AB. For. Manage. Note 32, pp 6.

Nationwide Forestry Applications Program. 1988. Utilization of High Altitude Photography for Natural Resource Management. USDA. For. Serv., Salt Lake City, UT. pp. 134. Revised.

Ward, J.D., R.E. Acciavatti and W.M. Ciesla. 1986. Mapping insect defoliation in eastern hardwood forests with color-IR aerial photos: a photo interpretation guide. USDA For. Serv., For. Pest Manage./Methods Applic. Group, Fort Collins, CO. pp. 25. 